\title{
Дятлов Р.H.
}

\section{Разветвлённый алгоритм в методе программированного обучения на базе образовательных онлайн-технологий}

\author{
Dyatlov R.N. \\ Branched algorithm in the method of programmed learning \\ on the basis of online education technology
}

\begin{abstract}
Статья посвящена актуализации современных образовательных Интернет-технологий применительно к методу программированного обучения. Отмечены достоинства автоматизированного и формализованного подхода при контролируемой самоподготовки ученика. Показана гибкость индивидуальных траекторий обучения при использовании разветвлённых алгоритмов
\end{abstract}

Ключевые слова: программированное обучение, алгоритм, компьютер, онлайн образование

\section{Дятлов Роман Николаевич}

Кандидат технических наук, доцент

Московский государственный

машиностроительный университет

г. Рязань, ул. Право-Лыбедская, 26/53

\begin{abstract}
The article is devoted to the actualization of modern educational Internet-technologies as applied to the method of programmed training. Noted advantages of automated and formalized approach to student self-controlled. It is shown that the flexibility of individual learning paths using the branching algorithms
\end{abstract}

Key words: programmed learning, algorithm, computer, online education

\section{Dyatlov Roman Nikolaevich \\ Candidate of Engineering Sciences, Associate Professor \\ Moscow state university of mechanical engineering Ryazan, Pravo-Lybedskaya st., 26/53}

В современном мире научно-технический прогресс развивается стремительными темпами и студентам высших образовательных учреждений требуется успевать за ограниченное время учебного процесса усваивать большое количество новой информации по дисциплинам. Для подготовки бакалавров и инженеров мирового уровня актуально совершенствовать методы учебного процесса, повышать скорость и качество преподносимой лекционной информации, увеличивать эффективность лабораторных и практических занятий, максимально разумно использовать контрольно-измерительные материалы на базе ЭВМ и компьютерных приложений в процессе обучения и проверки знаний учащихся, что создаст условия, при которых ученик будет вынужден систематически осваивать материалы курса.

Долговременные и глубокие знания приобретаются учеником в результате самостоятельной системной работы над курсом равномерно в течении всего учебного года и не «зубрёжка» формул, законов и методов расчёта, а непрерывное применение их к решению и анализу практических задач. Студент 
должен не только уметь пересказывать то, что конспектирует на лекциях или прочитал в учебниках, но и уметь применять теорию в реальных инженерных задачах. Проверить знания возможно с помощью задач, вопросов, игровых форм, в которых отражены практика и теория дисциплины.

Одним из положительно [1] зарекомендовавших себя методов обучения, который дополняет классическую систему образования, является программированное обучение. Первые попытки массово использовать этот метод в учебном процессе предпринимались с середины 20 века Центральным институтом труда в СССР и профессором Б. Ф. Скиннером в США [2]. В настоящее время этот метод интенсивно развивается и используется в развитых странах в связи с бурным развитием информационных и компьютерных технологий, дистанционных образовательных ресурсов в сети Интернет.

Суть программированного обучения заключается в методике создания программы-сценария, которая управляет учебной деятельностью учащихся в процессе освоения ими учебного материала. Современные системы управления электронными онлайн-курсами позволяют практически полностью автоматизировать, формализовать подачу и контроль освоения учебного материала. При этом роль педагога не теряется и не заменяется машинной обработкой данных, но существенно сокращает время оценки подготовки студента, делает этот процесс объективней и разгружает преподавателя от утомительной и непроизводительной работы, например, выслушивая неподготовленных учеников, рутинная механическая проверка тестовых заданий в печатной форме.

При информационном подходе к процессу усвоения рассматриваются только качественные и количественные характеристики информационного процесса. При этом следует учитывать такие факторы, как ограничение и дозировка информации на отдельных этапах усвоения по пропускной способности мозга человека при переработке им новой информации, структурные особенности информационных процессов и их влияние на получение опыта.

Главными принципами, заложенными в методе программированного обучения, являются:

- деление большого объёма материала на малые порции (шаги и кадры), чтобы ученики затрачивали минимум усилий для овладения содержимым;

- мгновенное подтверждение правильности ответа с положительным или отрицательным подкреплением результата (например, начисление баллов или штрафов);

- использование закрытых типов вопросов (выбор ответов из предложенных вариантов);

- наличие пояснений по всем вариантам ответа.

В общем виде весь процесс усвоения учебного материала сводится к выражению

$$
\mathrm{C} \rightarrow \mathrm{P} \rightarrow \Pi \text {, }
$$

где C - стимул (задание, вопрос), P - реакция (решение, ответ), П - подкрепление правильного ответа. Такое механическое закрепление материала слабо учитывает психические процессы, но позволяет ученику накопить информацию и приспособиться к внешнему контролю знаний. 
Разветвлённый алгоритм программированного обучения изобретён американским учёным-педагогом Норманом Кроудером. Различные модификации этого алгоритма реализуется сегодня в информационном образовательном пространстве всего мира. Метод основан на введении индивидуальных образовательных траекторий при прохождении учебного материала. Сценарий пути для каждого ученика определяется автоматизированной программой в процессе обучения, опираясь на ответы учащихся.

Много современных онлайн-систем дистанционного обучения технически позволяют реализовать идеи программированного обучения. Например, в популярной оболочке Moodle стандартный элемент «Лекция» обладает функциональными возможностями создания нелинейных обучающих траекторий.

Пример простого разветвлённого алгоритма по методу программированного обучения показан на рисунке 1 . В первую очередь необходимо подготовить подробный учебный материал и разделить его на $n$ малых логически завершённых частей - кадры. Кадры состоят из шагов.

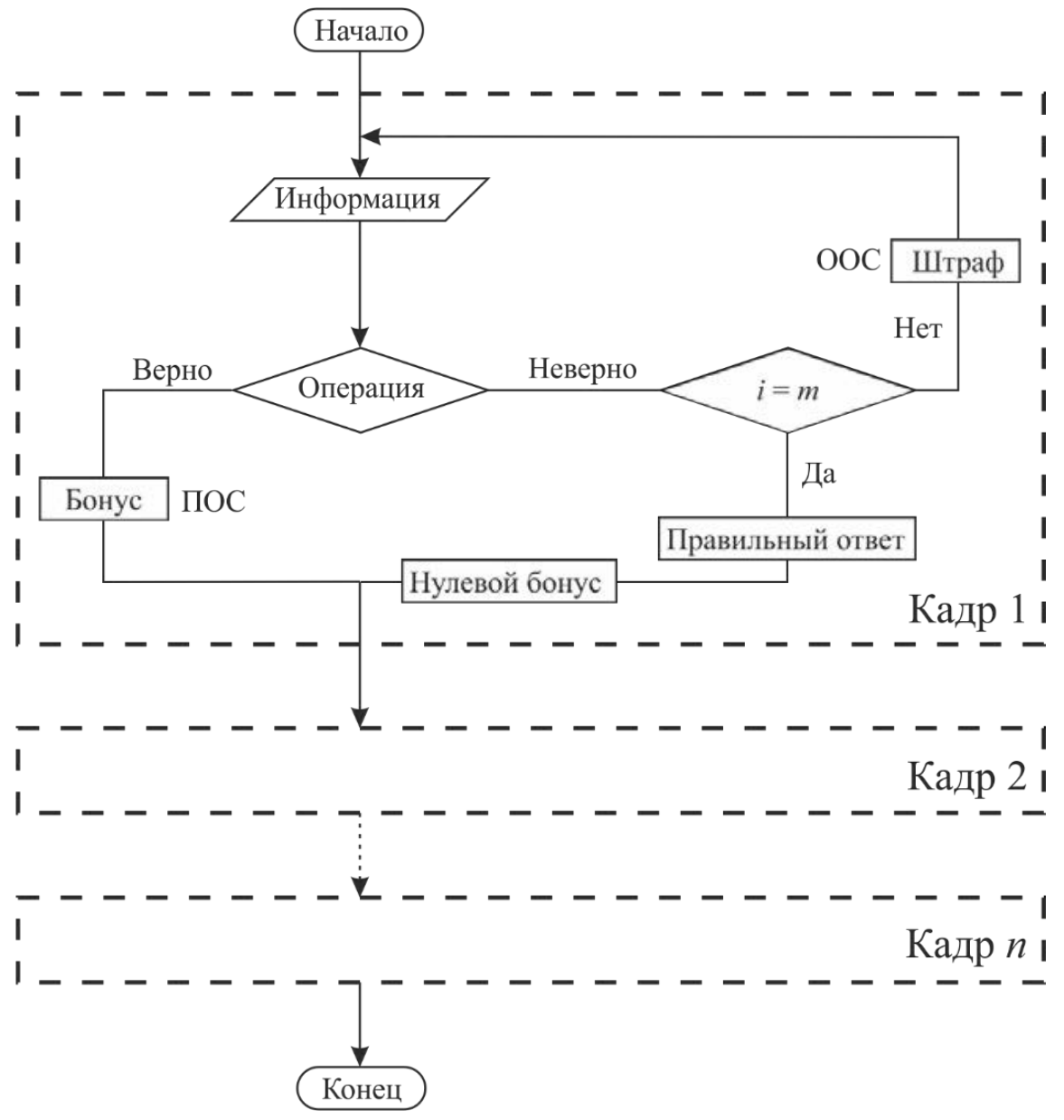

Рис. 1. Пример простого разветвлённого алгоритма по методу программированного обучения

Первый шаг - единица усваиваемой информации И. Размер шага в текстовом виде необходимо выбирать исходя из уровней сложности материала и подготовки ученика; в общем случае в пределах $30 \ldots 70$ слов.

Второй шаг - операция О. Операция предназначена для совершения действий учеником по отношению к первому шагу. Такими действиями могут 
быть ответы на контрольные тестовые вопросы, игровая форма, выполнение иных заданий подтверждающие усвоение материала первого шага.

Третий шаг - обратная связь системы с учеником. Обратная связь может быть положительной (ПОС) и отрицательная (ОOC) по отношению к студенту, а не к алгоритму. В первом случае за верный ответ ученику начисляются положительные баллы (бонус), во втором - отрицательные баллы за неверный ответ (штраф) с возвратом к первому шагу и повторному изучению учебного материала. Число неправильных ответов может быть ограниченно количеством $m$. Как только учащийся потратит все $m$ попыток на ответ система демонстрирует ему полное правильное решение с комментариями, зачисляет нуль баллов (нулевой бонус) за эпизод и переводит ученика на следующий информационный кадр.

Четвёртым шагом (не показан на рисунке 1) может быть внешний контроль К со стороны преподавателя.

Таким образом один информационный кадр усваиваемого материала состоит из информации И, операции О, обратной связи ОС и внешнего контроля К. Ограничивать ученика во времени при изучение материала не рекомендуется, так как это может создать у студента дискомфорт в восприятии информации. Количество заданий (вопросов) во втором шаге в некоторых случаях можно увеличить до трёх: а) формальное восприятие материала (читал или не читал); б) осмысленное изучение материала (нет явного ответа в первом шаге); в) простая практическая задача (расчёт по формулам). После каждой группы кадров ученику необходимо пройти контрольный тест на время по теме изученного материала, тем самым закрепить и проверить усвоенный материал.

Для разработки обучающих программ с полными кадрами могут быть использованы следующие модели:

1) И + O + ОС + К - для самостоятельного изучения нового материала;

2) $\mathrm{O}+\mathrm{OC}+$ И + K - при повторении изученного материала (например, после аудиторной лекции).

Метод программированного обучения не стремится подменить классическую образовательную модель. Роль педагога остаётся в полном объёме, изменяются только методы контроля усвоенных знаний студента и применение современных технологий для вовлечения ученика в самостоятельную работу. Разнообразные формы представления материала включая интерактивное и мультимедийное содержание, несомненно, вызовет заинтересованность добросовестных студентов в изучении преподаваемой дисциплины.

\section{Список используемых источников:}

1. Гальперин П.Я. Программированное обучение и задачи коренного усовершенствования методов обучения // К теории программированного обучения. М., 1967.

2. Беспалько В.П. Программированное обучение. Дидактические основы. М.: Высшая школа, 1970.300 с.

(C) 2015, Дятлов Р.Н.

Разветвлённый алгоритм в методе программированного обучения на базе образовательных онлайн-технологий
(C) 2015, Dyatlov R.N.

Branched algorithm in the method of programmed learning on the basis of online education technology 